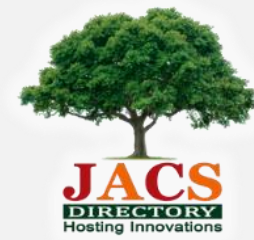

Journal of Environmental Science and Pollution Research

Visit Journal at https://www.jacsdirectory.com/jespr

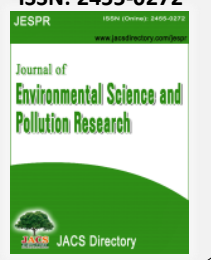

\title{
Fabrication of Composite-Based Electrospun Nanofiber Adsorbent and Application in Dye Removal
}

\author{
K. Selvakumar*, G. Venkat Kumar \\ Department of Biotechnology, PRIST University, ECR Campus, Chennai - 603 102, Tamil Nadu, India.
}

\section{ART IC LE DETAILS}

Article history:

Received 30 November 2020

Accepted 8 December 2020

Available online 13 December 2020

\section{Keywords:}

Silica Nanoparticles

Graphene Oxide Nanoparticles

Methylene Blue

Dye Removal

\begin{abstract}
A B S T R A C T
The improvement of processes for maintaining our ecosystem amidst rapidly developing and sustaining pollution is the ever-growing demand. This current research work is aimed at developing useful nanomaterials, such as silica nanoparticles and graphene oxide nanoparticles from solid agro-waste, coconut husk. The nanoparticles obtained were then blended with two other polymers, namely polyhydroxyalkanotes, a microbial biopolymer and polyvinylpyrrolidone, a synthetic biodegradable polymer to form nanocomposites, which are used as the base for nanofiber fabrication through electrospinning. The nanocomposites were characterized through Fourier-transform infrared (FTIR) spectrometer and the nanofibers under scanning electron microscope. The nanofibers were subjected to analyze the ability to function as adsorbents. The composite nanofibers developed were able to remove $62 \%$ of methylene blue dye in the test solution in a span of 12 hours with additional benefits of easy removal of used adsorbents and adsorbates.
\end{abstract}

\section{Introduction}

Land, water and atmosphere are the greatest resources of the earth which combine to provide a habitable environment to human beings along with other organisms. The continuous utilization of resources in different ways leads to form undesirable byproducts, which are collectively termed as pollutants and that process is termed as pollution. Among different types of dangerous pollution, water pollution is the one drawing more attention owing to fact that water is an essential need of almost all of the living organisms. Although the level of water in the earth is high, the amount of potable water available for consumption is really less. Among different pollutants, the dye is one of the major influencers which contribute to both aesthetic and health issues on release into the water resources [1].

Although different sectors of science and technology contribute their part in the water treatment and purification methodology, the role of biotechnology and nanotechnology is becoming remarkable. Nanotechnology is a fascinating technology, which is a product of a very old nanoscience discipline. It has now become an integral part of every science and technology discipline as a result of the unexplored surprising properties of every material at its nanoscale (1 to $100 \mathrm{~nm})$ size. The efficiency of nano-sized materials extends towards involvement in environmental management [2]. With highly limited size, expanded surface area, cost-effectiveness and efficient properties, nanomaterials are prominent leads for all types of environmental remediation applications. Different nanomaterials are being researched and reported so far for their application in the water treatment process especially in the dye removal process. Nanoparticles and nanofibers are two of the notable forms of nanotechnology that are being analyzed for efficiency in dye removal through different processes, namely adsorption, photocatalysis, filtration, etc., [3].

While focusing on water treatment, the focus cannot be taken away from the solid wastes that pollute the soil environment. Effective and profitable solid waste management strategy is also an important need of the hour. The accumulation of agro-waste in the cultivation and processing areas is increasingly high in recent years. Coconut is being produced as one of the important foods and oil sources around the world. More than 20 million tons of coconut wastes are directly or indirectly being dumped in our ecosystem every year [4]. Being one of the top producers of coconut,

the estimated wastage of coconut agriculture and processing industries in India is very high. Approximately 1.8 metric tons of coconut wastes are being generated in India by 2016 [4]. Value addition activities highly depend on the quality of these coconut waste materials. However, the current research focuses on the ash material that is being produced from coconut waste under controlled conditions. This makes freedom from the quality of coconut wastes. Therefore, it provides possible ways to use even the poor quality coconut wastes, which cannot be used on priority in other waste utilization processes. It is a part of the objective of this current research to use this agro-waste efficiently.

This current research work is aimed at producing graphene oxide nanoparticles and silica nanoparticles from the coconut husks and involving the same in nanocomposite nanofiber fabrication using electrospinning by blending with biodegradable polymers, such as polyhydroxyalkanotes and polyvinylpyrrolidone. The nanofiber is then tested for its adsorptive efficiency on methylene blue dye removal.

\section{Experimental Methods}

\subsection{Biomaterial Preparation from Cocos nucifera Drupe}

Coconuts used in the research were purchased from the local market in Ambattur, Chennai. The Cocos nucifera drupe obtained from the local market was washed thoroughly and wiped with tissue paper. The whole coconut was weighed using a weighing scale. The outer epicarp and mesocarp (husk fiber part) of the coconut were removed carefully using a billhook. The inner coconut shell with the fruit was removed separately. The coconut fibers were chopped into small lengths using scissors. The chopped husk was then placed in a hot air oven for drying at $80^{\circ} \mathrm{C}$ for 12 hours. The $50 \mathrm{~g}$ coconut husk was taken, cleaned and dried. The fiber was then pyrolyzed to produce ash in a muffle furnace for 5 hours at $700{ }^{\circ} \mathrm{C}$. The ash biomaterial obtained as a result was powdered using a laboratory grinder and sieved using very fine mesh [5-7].

\subsection{Silica Nanoparticles Synthesis}

The chemicals used in this research were obtained from Merck India. 5 g of coconut husk ash was then mixed with $50 \mathrm{~mL}$ of $2.5 \mathrm{~N}$ sodium hydroxide solution and kept in a hot plate cum magnetic stirrer at $100{ }^{\circ} \mathrm{C}$ for 4 hours. After 4 hours, the sodium silicate solution was filtered using Whatman No. 41 ashless filter paper. $20 \mathrm{~mL}$ of the sodium silicate solution was taken in a clean borosilicate beaker. $2 \mathrm{M}$ hydrochloric acid was added to this mixture in a dropwise manner continuously. The addition of 
hydrochloric acid is terminated on the formation of a white gel. The beaker was then covered with aluminum foil and kept undisturbed for 24 hours. After the aging period, the solution with the precipitate was centrifuged at $5000 \mathrm{rpm}$ for $15 \mathrm{~min}$. The supernatant was discarded and the white precipitate was collected and washed thrice in distilled water in a hot air oven for 2 hours at $60^{\circ} \mathrm{C}$. The white precipitate of silica thus obtained was further mixed with $1 \mathrm{M}$ hydrochloric acid in the ratio 1:10. The mixture was kept in a hot plate cum stirrer for 3 hours at $250 \mathrm{rpm}$. The heat was maintained at $100{ }^{\circ} \mathrm{C}$. Following stirring, the silica nanoparticles were obtained by centrifuging the same at $5000 \mathrm{rpm}$ for $5 \mathrm{~min}$. The collected nanoparticles were dried in a hot air oven at $50{ }^{\circ} \mathrm{C}$ for 4 hours [8].

\subsection{Graphene Oxide Nanoparticles Synthesis}

$5 \mathrm{~g}$ of coconut husk ash was mixed in $50 \mathrm{~mL}$ of $2 \mathrm{M}$ sodium hydroxide solution and kept for stirring in a magnetic stirrer with a hot plate at $70^{\circ} \mathrm{C}$ for 4 hours. The solution was then filtered using Whatman No. 41 ashless filter paper. The residue trapped in the filter paper was dried, scrapped and used as a carbonized material base for graphene oxide synthesis. The carbonized material was washed using dilute hydrochloric acid and dried in a hot air oven at $60^{\circ} \mathrm{C}$ for 2 hours. $90 \mathrm{~mL}$ of sulphuric acid and $10 \mathrm{~mL}$ of orthophosphoric acid were mixed and placed on a magnetic stirrer at 100 rpm. $1 \mathrm{~g}$ of carbonized material and $6 \mathrm{~g}$ of potassium permanganate were mixed and the mixture was added into the acid mixture under stirring conditions slowly without creating any fumes. The composition was kept stirring for 12 hours at the temperature of $50{ }^{\circ} \mathrm{C}$. After stirring, $30 \mathrm{~mL}$ of $30 \% \mathrm{H}_{2} \mathrm{O}_{2}$ was slowly added into the mixture and mixed well. Then the mixture was removed from the stirrer and placed in an ice bath to reduce the heat to room temperature. $100 \mathrm{ml}$ of cold distilled water was added to the mixture, mixed well and kept for centrifugation at $3500 \mathrm{rpm}$ for 5 minutes. After centrifugation, the supernatant was discarded and the pellet was collected. The pellet was subjected to acid wash with $10 \mathrm{~mL}$ of $30 \%$ hydrochloric acid for two subsequent times. Following the acid wash, the pellet was subjected to ethanol wash with $10 \mathrm{~mL}$ of $70 \%$ ethanol. Finally, the pellet was collected and dried in a hot air oven overnight at 80 ${ }^{\circ} \mathrm{C}$. After drying, the pellet was finely ground and used for further experiments $[9,10]$.

\subsection{Nanocomposites Preparation}

$10 \mathrm{~g}$ of polyhydroxyalkanotes (PHA) beads were weighed and mixed with $100 \mathrm{~mL}$ of chloroform. The mixture was kept in stirring for 30 minutes at $200 \mathrm{rpm}$ for the complete dissolving of the bioplastic. $2.5 \mathrm{~g}$ of polyvinylpyrrolidone (PVP) was added to the PHA solution and stirring was continued for 30 more minutes. Then $1 \mathrm{~g}$ of dried silica nanoparticles was added to the mixture and the solution was vigorously stirred for 15 min. Then $1 \mathrm{~g}$ of dry graphene oxide nanoparticles was added to the mixture and vigorous stirring was further continued till a clear solution was obtained. The solution was checked for $\mathrm{pH}$ and stored in refrigerated conditions for further usage [11].

\subsection{FTIR Analysis of Nanocomposites}

The polymeric precursor nanocomposites solution was analyzed using Fourier-transform infrared spectroscopy (FTIR) (Shimadzu). The infrared spectra of the sample were analyzed and recorded in the region of 500 to $4000 \mathrm{~cm}^{-1}[12]$.

\subsection{Nanofibers Production through Electrospinning}

The polymeric precursor solution for nanofibers production was prepared using nanocomposites in the concentration of $10 \%(\mathrm{w} / \mathrm{v}) .10 \mathrm{~g}$ of the composites was dissolved in $100 \mathrm{~mL}$ of chloroform and stirred in a hot plate cum stirrer for 30 minutes at $250 \mathrm{rpm}$. The solution was taken in a $2 \mathrm{~mL}$ syringe and loaded in the electrospinning equipment. The syringe was fixed at a distance of $20 \mathrm{~cm}$ from the collector. The voltage supply was fixed at $20 \mathrm{kV}$ and the flow rate was adjusted to $40 \mu \mathrm{L} / \mathrm{min}$. The nanofibers produced were collected in a rotary drum collected fixed with aluminium foil [13].

\subsection{Scanning Electron Microscopical Analysis of Nanocomposite Fibers}

The surface morphology of the nanofibers was studied using scanning electron microscope (SEM). The nanofibers were cut into small pieces ( 5 $\mathrm{mm} \times 5 \mathrm{~mm}$ ) and mounted in the stub made of aluminum. The sample was fixed using the carbon adhesive tape (double-sided). The stub with specimen was coated with a thin layer of gold and subjected to microscopical analysis. TESCAN-VEGA3 scanning electron microscope was used for the SEM analysis. The sample was viewed under different ranges of magnification [14].

https://doi.org/10.30799/jespr.209.20060204

\subsection{Dye Removal Experiment with Nanocomposite Fibers}

$10 \mathrm{~mL}$ of methylene blue dye solution (at different concentrations) was taken in a $15 \mathrm{~mL}$ clean test tube. $100 \mathrm{mg}$ of electrospun nanofiber adsorbent was added to each tube. The tubes were kept in an orbital shaker at $27^{\circ} \mathrm{C}$ for 12 hours. After the stirring period, $2 \mathrm{~mL}$ of solution was taken from the test tube and analyzed using a spectrophotometer at 609 $\mathrm{nm}$ [15]. The results were tabulated. The adsorption capacity of the electrospun nanofibers was calculated using the following formula:

$$
\mathrm{q}_{e}=\frac{\left(C_{o}-C_{e}\right) \mathrm{V}}{m}
$$

where, qe $=$ Adsorption capacity of the adsorbent $(\mathrm{mg} / \mathrm{g})$

$$
\begin{aligned}
& \mathrm{C}_{\mathrm{o}}=\text { Initial concentration of the dye }(\mathrm{mg} / \mathrm{L}) \\
& \mathrm{C}_{\mathrm{e}}=\text { Final concentration of the dye at equilibrium }(\mathrm{mg} / \mathrm{L}) \\
& \mathrm{V}=\text { Total volume of the dye solution }(\mathrm{L}) \\
& \mathrm{m}=\text { Mass of the nanofiber adsorbent }(\mathrm{g}) .
\end{aligned}
$$

\section{Results and Discussion}

\subsection{Coconut Husk Ash Preparation}

The husk required for producing coconut ash was obtained from the dry coconut purchased from the local market (Fig. 1a). The outer part of the coconut was removed using a billhook and the coconut husk was collected (Fig. 1b) and powdered (Fig. 1c). Finally the prepared ash thus produced was collected and used for further experiments (Fig. 1d). Coconut husk has been reported as one of the valuable sources for nanomaterial production [16]. Coconut ash is produced through controlled pyrolysis under muffled conditions using a muffle furnace. Pyrolysis performed with little or no oxygen condition helps in increasing the carbon and decreasing the hydrogen and oxygen content of the coconut waste material being subjected to pyrolysis. The higher rate of increasing temperature during the pyrolysis helps in producing carbon material with a high surface ratio [17].

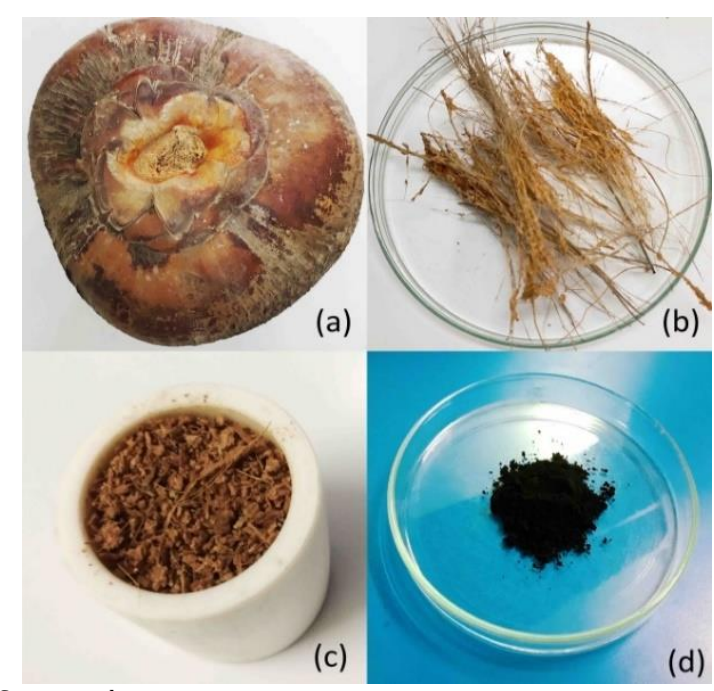

Fig. 1 Coconut ash preparation

\subsection{Nanoparticles Preparation}

Silica nanoparticles were produced from the coconut husk ash using the procedure proposed by Yadav et al., [8]. Approximately $12 \%$ of white precipitate of silica nanoparticles was obtained from the coconut ash base (Results not provided here). Graphene oxide nanoparticles were produced with the modified procedures of Marcano, and Grace et al. [9,10]. 23\% of graphene oxide nanoparticles were obtained as the final yield from the experiment.

\subsection{Nanocomposites Preparation}

To develop a better adsorbent, the nanoparticles were developed into a composite formulation along with polymers to finally develop into nanofibers. Graphene oxide and silica nanoparticles were mixed along with two biodegradable polymers, namely polyhydroxyalkanoates and polyvinylpyrrolidone. The polymers assist greatly in the nanofibers synthesis. Different concentrations of the polymers were tested at the lab level and the final concentration of 4:1 (polyhydroxyalkanotes: polyvinylpyrrolidone) has been found to be optimum for nanofibers synthesis. 
Both the polymers were found to be non-toxic, biodegradable and hydrophobic. The biodegradable nature of both the polymers helped to dispose of the fibers after usage without adding much burden to the environment. Hydrophobicity helps in their surplus water-based applications. The nanocomposites possess a high surface to volume ratio and possess better mechanical properties than the individual components [18]. Hence, using the nanocomposites formulation for the development of nanofibers renders better functionality for the final adsorbents, such as high adsorption power and good mechanical strength and durability.

\subsection{Biocomposite Nanofibers}

The nanocomposites were made into nanofibers form through the electrospinning technique (Fig. 2). Among different techniques in nanofibers production, electrospinning was chosen due to the varied advantages rendered by the same. Electrospinning helps to produce nanowoven fabrics in nanometer size with a higher volume to surface ratio. It is the simplest technique comparing to other techniques and can be upscaled for mass production relatively easier. Apart from the same, electrospinning is reported to be more suitable for developing nanofibers when nanomaterials-reinforced composites are involved as a base in the production [19]. Biocomposite nanofibers thus produced were light in weight and were light greyish in color due to the presence of graphene oxide nanoparticles (Fig. 2d).

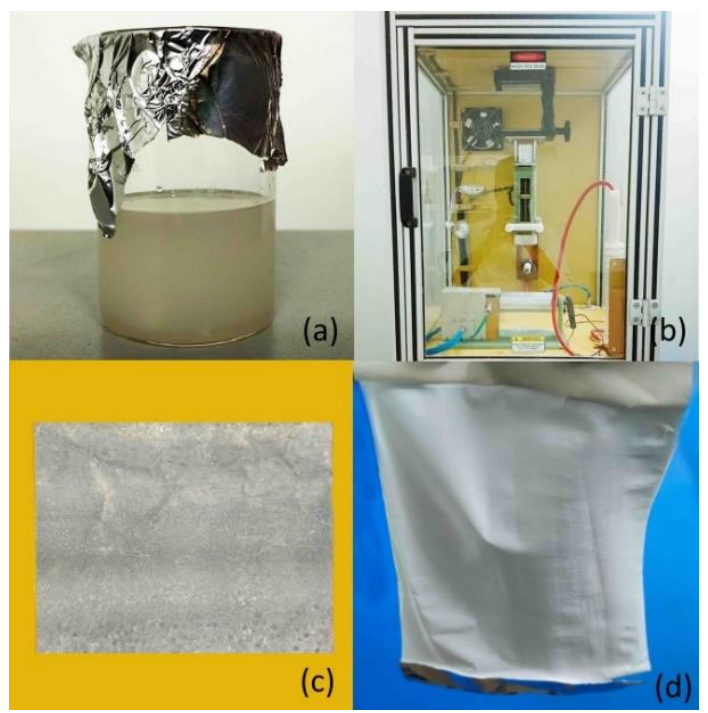

Fig. 2 Nanocomposite nanofibers fabrication

\subsection{FTIR Analysis of Nanocomposites}

The nanocomposites were subjected to Fourier-transform infrared spectrometric analysis to confirm the presence of their components (Fig. 3).

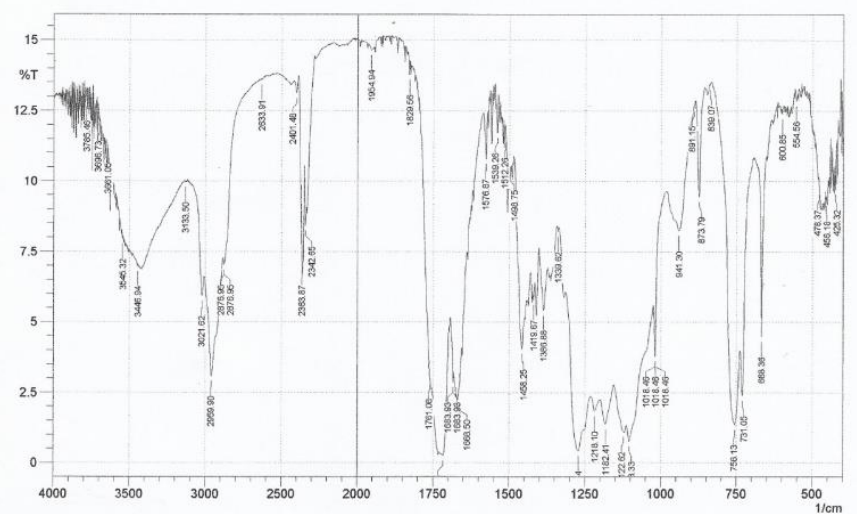

Fig. 3 Biodegradable nanocomposite fibers (attached to the surface)

The peak at $478 \mathrm{~cm}^{-1}$ arose due to the vibration of $\mathrm{Si}-\mathrm{O}-\mathrm{Si}$ of the silica nanoparticles. The peak at $1018 \mathrm{~cm}^{-1}$ confirmed the presence of silica nanoparticles. The peaks at the high-frequency areas $3446 \mathrm{~cm}^{-1}$ were attributed to the $\mathrm{O}-\mathrm{H}$ bond stretching. This confirms the hydroxyl group's presence in the graphene oxide nanoparticles. Peaks in the range of 1668 to $1683 \mathrm{~cm}^{-1}$ confirmed the presence of graphene oxide nanoparticles in the composite. A peak in the range of $1339 \mathrm{~cm}^{-1}$ corresponds to $\mathrm{C}-\mathrm{OH}$ group of graphene oxide. The peak at $1668 \mathrm{~cm}^{-1}$ corresponds to the amide https://doi.org/10.30799/jespr.209.20060204 group of polyvinylpyrrolidone. Peaks at $756 \mathrm{~cm}^{-1}$ relate to the $\mathrm{C}-\mathrm{C}$ chain of PVP. The presence of PHA can be confirmed by $\mathrm{CH}, \mathrm{CH}_{2}, \mathrm{CH}_{3}$ groups which were present in the $2959 \mathrm{~cm}^{-1}$ region [20-23].

\subsection{SEM Analysis of Composite Nanofibers}

The nanofibers produced were subjected to scanning electron microscopical analysis. The images were produced at different resolutions. In this research work, the nanofibers have been produced in the size range of 74.99 to $189.94 \mathrm{~nm}$ (Fig. 4).

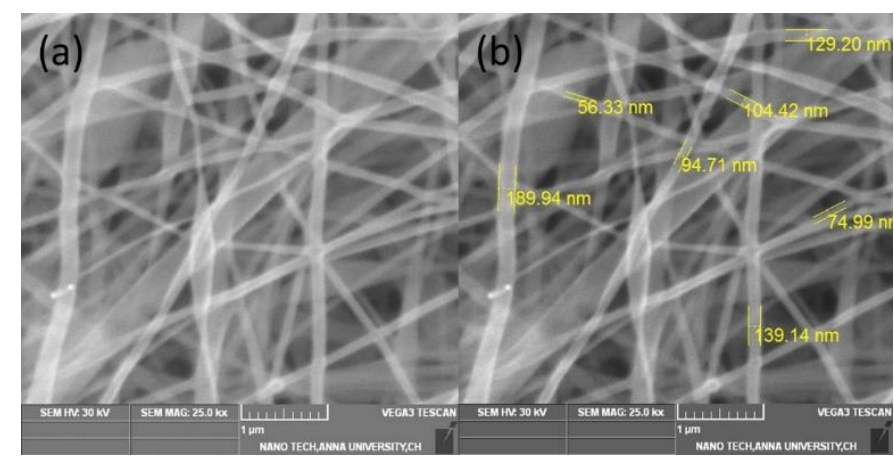

Fig. 4 Scanning electron microscopical images of nanofibers (at $1 \mu \mathrm{m}$ scaling)

\subsection{Dye Absorption Studies}

Experiments were performed for the silica nanoparticles, graphene oxide nanoparticles and composite electrospun nanofibers individually to assess their efficiency in methylene blue adsorption. This is to compare the absorption efficiency of nanoparticles in free form to that of those in composite form. Among the two different nanoparticles tested for adsorption efficiency, the graphene oxide nanoparticles have shown better performance in 12 hours of testing. The initial dye concentration in the test solution was $20 \mu \mathrm{g}$ per mL. The final dye concentration in the solution after 12 hours of adsorption study was $0.95 \mu \mathrm{g}$ per mL. Graphene oxide nanoparticles have been found to remove nearly $95.25 \%$ of the dye present in the solution in a span of 12 hours (Fig. 5).

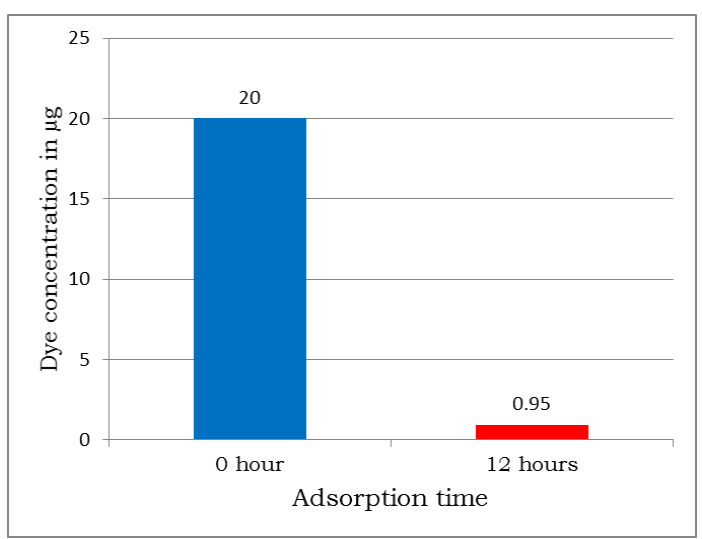

Fig. 5 Methylene blue adsorption by graphene oxide nanoparticles

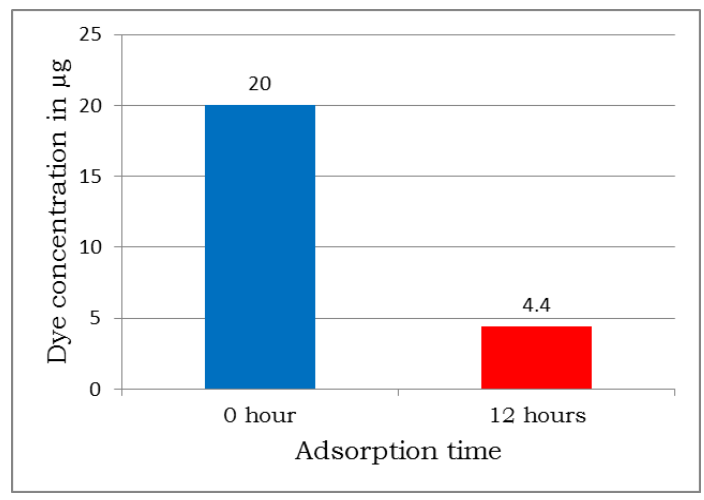

Fig. 6 Methylene blue adsorption by silica nanoparticles

Silica nanoparticles were also found to have removed methylene blue through adsorption. In twelve hours experiment, silica nanoparticles can be able to absorb $78 \%$ of the dye present in the solution (Fig. 6). Silica is reported to be a good sorbent of dye. Up to $80 \%$ removal of the methylene blue was reported by Enrique C. Peres et al. [24]. The performance of 
graphene oxide nanoparticles in the removal of dye is better than the silica nanoparticles. Graphene in both bulk and nano form has been reported to remove methylene blue through adsorption as well as degradation [2527]. The composite nanofibers removed $62 \%$ of the dye in the experimental solution in a span of 12 hours (Fig. 7). The Fig. 8 shows the concentration dye solution before (Fig. 8a) and after treating with nanofibres for 12 hours (Fig. 8b) and 36 hours (Fig. 8c).

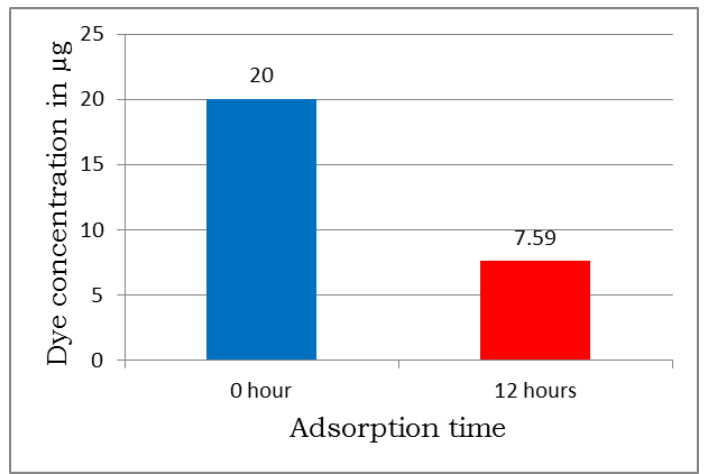

Fig. 7 Methylene blue adsorption by composite nanofibres

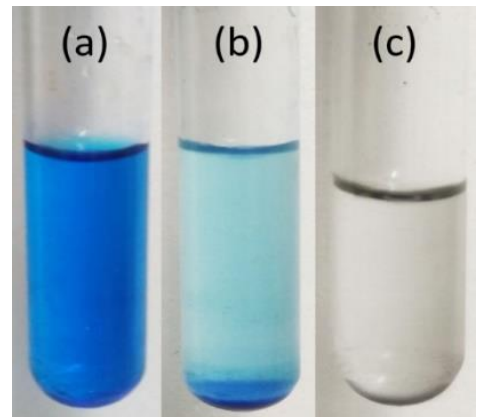

Fig. 8 Methylene blue dye visual images (a) before and (b) after treating with nanofibres for 12 hours and (c)36 hours

The reduction in the ability of adsorption in the nanofibers than the free form was due to the fact that in nanofiber forms the availability of the nanomaterials was less in comparison to the free form. However, the nanofiber forms were still able to produce nearly $75 \%$ of what free form nanoparticles can achieve.

\section{Conclusion}

The development and application of nanofiber adsorbents enriched with nanoparticles help in easy application of fiber materials for the dye treatment and also for easy removal of the adsorbed dyes from the treatment plant relatively easier than employing nanomaterials directly in the water treatment process. In this research we could able to produce silica nanoparticles and graphene oxide nanoparticles from coconut ash with the yield of $12 \%$ and $23 \%$ respectively. The ratio of the components in nanocomposite aids in smooth electrospinning process which produced an effective and degradable nanofiber. On testing the composite nanofibre proved efficiency to remove nearly $62 \%$ of the dye composition in the polluted water. Further research is required to upscale the fabrication process and to implement the same in a wider level.

\section{Acknowledgment}

The authors are thankful to BioLim Centre for Science \& Technology, Chennai for the providence of lab space and technical support in carrying out the work.

\section{References}

[1] S. Khan, A. Malik, Toxicity evaluation of textile effluents and role of native soil bacterium in biodegradation of a textile dye, Environ. Sci. Pollut. Res. 25(5) (2018) 4446-4458.

[2] S. Bayda, M. Adeel, T. Tuccinardi, M. Cordani, F. Rizzolio, The History of nanoscience and nanotechnology: From chemical-physical applications to nanomedicine, Molecules 25(1) (2019) 112-126.

[3] S.A. Umoren, U.J. Etim, A.U. Israel, Adsorption of methylene blue from industrial effluent using poly (vinyl alcohol), J. Mater. Environ. Sci. 4(1) (2013) 75-86.

[4] R. Becker, T. Queiroz, F. Santos, M. Cristian T. Pereira, R. Bohrer, et al., Productivity potential and coconut waste quality for biorefining, Agron. Sci. Biotechnol. 2(1) (2016) 11-20.

[5] Abdeljaoued, N. Querejeta, I. Durán, N.A. Gutiérrez, C. Pevida, et al., Preparation and evaluation of a coconut shell-based activated carbon for $\mathrm{CO}_{2} / \mathrm{CH}_{4}$ separation, Energies 11 (2018) 1748-1761.

[6] L. Mishra, G. Basu, Coconut fibre: Its structure, properties and applications, in: R.M. Kozłowski, M. Mackiewicz-Talarczyk (Eds.), Handbook of Natural Fibres, Woodhead publishing, United Kingdom, 2020, pp.232-255.

[7] S. Sivasubramanian, K. Sravanthi, Synthesis and characterisation of silica nano articles from coconut shell, Int. J. Pharm. Bio. Sci. 6(1) (2015) 530-536.

[8] V. Yadav, M.H. Fulekar, Green synthesis and characterization of amorphous silica nanoparticles from fly ash, Mater. Today 18(7) (2019) 4351-4359.

[9] D.C. Marcano, D.V. Kosynkin, J.M. Berlin, A. Sinitskii, Z. Sun, et al., Correction to improved synthesis of graphene oxide, ACS Nano. 12(2) (2018) 2078-2078.

[10] A.S. Grace, G.S.P.L. Malar, Synthesis and characterization of graphene oxide from coconut husk ash, Orient. J. Chem. 36(2) (2020) 348-352.

[11] G. Ghaderi, H. Tavanai, M. Bazarganipour, Electrospun graphene oxide incorporated PAN nanofibers, before and after activation, IOP Publishing Ltd. Mater. Res. Express 6(10) (2019) 105047-105087.

[12] M. Ramesan, Synthesis, characterization, and properties of new conducting polyaniline/copper sulfide nanocomposites, Polym. Eng. Sci. 54 (2014) 438445.

[13] Y. Lee, N. Sridewi, S. Ramanathan, K. Sudesh, The Influence of electrospinning parameters and drug loading on polyhydroxyalkanoate (PHA) nanofibers for drug delivery, Int. J. Biotechnol. Wellness Ind. 4 (2015) 103-113.

[14] W. Ruangudomsakul, C. Ruksakulpiwat, Y. Ruksakulpiwat, Preparation and characterization of cellulose nanofibers from cassava pulp, Macromol. Symp. 354 (2015) 170-176.

[15] C. Akduman, E.P.A. Kumbasar, S. Morsunbul, Electrospun nanofiber membranes for adsorption of dye molecules from textile wastewater, IOP Conf. Series: Mater. Sci. Eng. 254 (2017) 102001-102007.

[16] J.J. Monserate, J.R. Salazar, A.M. Tuates Jr., O.A. Capariño, Synthesis and characterization of nanocomposites from coconut waste (coconut husk): A new potential material for nano- filtration system, Asian J. Appl. Sci. 4(5) (2016) 1163- 1171.

[17] G. Tan, Y. Liu, D. Xiao, Influence of different pyrolysis methods on the sorption property of rice straw biochar, Sep. Sci. Technol. 54(17) (2019) 2773-2782.

[18] E. Mikličanin, A. Badnjević, A. Kazlagić, M. Hajlovac, Nanocomposites: a brief review, Health Technol. 10 (2020) 51-59.

[19] S. Agarwal, J.H. Wendorff, A. Greiner, Use of electrospinning technique for biomedical applications, Polymer. 49(26) (2008) 5603-5621.

[20] M. Hamdy, Zidan, M.E. Abdelrazek, M.A. Abdelghany, E. Ahmed, Tarabiah, characterization and some physical studies of PVA/PVP filled with MWCNTs, J. Mater. Res. 8(1) (2019) 904-913.

[21] Shah, Kamlesh, FTIR analysis of polyhydroxyalkanoates by a locally isolated novel Bacillus sp. AS 3-2 from soil of Kadi region, North Gujarat, India, J. Biochem. Technol. 3 (2012) 380-383.

[22] M. Yazdimamaghani, T. Pourvala, E. Motamedi, B. Fathi, D. Vashaee, et al., Synthesis and characterization of encapsulated nanosilica particles with an acrylic copolymer by in situ emulsion polymerization using thermoresponsive nonionic surfactant, Materials 6 (2013) 3727-3741.

[23] D. Khalili, Graphene oxide: a promising carbocatalyst for the regioselective thiocyanation of aromatic amines, phenols, anisols and enolizable ketones by hydrogen peroxide/KSCN in water, New J. Chem. 37 (2016) 1-9.

[24] V. Siong, K. Lee, J. Juan, C. L. Tai, et al., Removal of methylene blue dye by solvothermally reduced graphene oxide: a metal-free adsorption and photodegradation method, RSC Adv. 9 (2019) 37686-37695.

[25] E.C. Peres, J.C. Slaviero, A.M. Cunha, A. Hosseini-Bandegharaei, G.L. Dotto, Microwave synthesis of silica nanoparticles and its application for methylene blue adsorption, J. Environ. Chem. Eng. 6(1) (2018) 649-659.

[26] E.F. Aboelfetoh, A.H. Gemeay, R.G. El-Sharkawy, Effective disposal of methylene blue using green immobilized silver nanoparticles on graphene oxide and reduced graphene oxide sheets through one-pot synthesis, Environ. Monit. Assess. 192 (355) (2020) 1-20.

[27] C.H. Chia, N.F. Razali, M.S. Sajab, S Zakaria, N.M. Huang, et al., Methylene blue adsorption on graphene oxide, Sains Malays. 42 (2013) 819-826. 